\title{
Effect of Locally Applied Transforming Growth Factor Beta3 on Wound Healing and Stenosis Development in Tracheal Surgery
}

\author{
Aykut Eliçora MD, Serife T Liman MD, Betul Arıca Yegin PhD, Aslı G Akgül MD, \\ Hakan Eroglu PhD, Kursat Yildiz MD, Salih Topcu MD, and Cuneyt Ozer DVM
}

\begin{abstract}
BACKGROUND: Tracheal stenosis constitutes one of the most frequently seen problems in thoracic surgery. Although many treatment modalities to prevent fibroblast proliferation, angiogenesis, or inflammation that causes tracheal stenosis have been attempted, an effective method has not yet been found. In this study, a transforming growth factor beta3 (TGF- $\beta 3$ )/chitosan combination was used for this purpose. METHODS: A slow-release preparation containing a thin layer of TGF- $\beta 3$ with a chitosan base was made. Thirty albino Wistar rats were divided into 3 groups. A full-layer vertical incision was made in the anterior side of the trachea of each rat between the second and fifth tracheal rings. The tracheal incision was sutured. Group A was evaluated as the control group. In Group B, a chitosan-based film was placed on the incision line. In Group C, a slow-release TGF-ß33/chitosan-coated substance was placed on the incision line. The rats were killed on day 30, and their tracheas were excised by cutting between the lower edge of the thyroid cartilage and the upper edge of the sixth tracheal ring together with the esophagus. Epithelialization, fibroblast proliferation, angiogenesis, inflammation, and collagen levels were evaluated histopathologically by the same histopathologist. RESULTS: Statistically significant differences were not found among the 3 groups. Cold abscesses were observed at the incision sites in both the TGF- $\beta /$ chitosan and chitosan groups. These were thought to have formed due to the chitosan. CONCLUSIONS: As this was the first experiment in the literature to use this type of TGF- $\beta 3$ formulation, we intend to change the formulation and perform this study again with a different TGF- $\beta 3 /$ chitosan preparation. Key words: TGF- $\beta 3$; trachea; stenosis; surgery. [Respir Care 2014;59(8):1281-1286. () 2014 Daedalus Enterprises]
\end{abstract}

\section{Introduction}

Various treatment methods have been developed for benign and malignant tracheal lesions. Bronchoscopic dila-

Drs Eliçora, Liman, Akgül, and Topcu are affiliated with the Thoracic Surgery Department; Dr Yildiz is affiliated with the Pathology Department; and Mr Ozer is affiliated with the Experimental Research Unit, Faculty of Medicine, Kocaeli University, Kocaeli, Turkey. Dr Yegin and Dr Eroglu are affiliated with Department of Pharmaceutical Technology, Faculty of Pharmacy, Hacettepe University, Ankara, Turkey.

The authors have disclosed no conflicts of interest.

Correspondence: Aykut Eliçora MD, Thoracic Surgery Department, Faculty of Medicine, Kocaeli University, Umuttepe Campus, 41380 Kocaeli, Turkey. E-mail: aykutelicora@yahoo.com.tr.

DOI: $10.4187 /$ respcare.02357 tation, stent placement, laser treatment, and surgical resection and reconstruction are among these treatment methods. The most important cause of treatment failure following surgical resection and tip-to-tip anastomosis is stenosis development. ${ }^{1-3}$

Several additional methods have been used to increase the efficacy of the surgical treatment. Antibiotics and corticosteroids are frequently used for this purpose. In addition to these, a slow-release 5-fluorouracil triamcinolone compound, mitomycin $\mathrm{C}$, hyperbaric oxygen, carnitine, and halofuginone are applied during treatment. There have been investigations into various wound-healing regulator agents. In recent years, many studies have been conducted to evaluate the effects of transforming growth factor beta1 (TGF- $\beta 1$ ), TGF- $\beta 2$, and TGF- $\beta 3$ on wound healing. TGF$\beta 1$, TGF- $\beta 2$, and TGF- $\beta 3$ are cytokines that are known for their efficacy at every level of wound healing. ${ }^{4}$ TGF- $\beta 3$ decreases scar tissue, whereas TGF- $\beta 1$ and TGF- $\beta 2$ in- 
crease collagen synthesis. ${ }^{1}$ The aim of this study was to determine the role of locally applied TGF- $\beta 3$ in preventing tracheal stenosis after tracheal surgery.

\section{Methods}

This study was carried out at the Experimental Medicine Research and Application Center of the Faculty of Medicine of Kocaeli University with the approval of the animal testing ethics committee of the Faculty of Medicine of Kocaeli University (No. 2/1-2011).

By melting it in a base of chitosan, recombinant human TGF- $\beta 3$ (R\&D Systems, Minneapolis, Minnesota), which is protected by a cold chain, was made into a slow-release film layer $(5 \times 5 \mathrm{~mm})$. The intention of this adaptation was that TGF- $\beta 3$ would be effective at every level of wound healing.

Thirty male albino Wistar rats, each weighing between 250 and $300 \mathrm{~g}$ (average weight of $280 \mathrm{~g}$ ), were used in the study. Rats were divided into 3 groups $(\mathrm{A}-\mathrm{C})$ of 10 . Groups A-C were defined as control, base (chitosan), and active ingredient + base (TGF- $\beta 3 /$ chitosan), respectively.

Rats were anesthetized with an application of $90 \mathrm{mg} / \mathrm{kg}$ ketamine hydrochloride (Ketalar, 10-mL flacon, Pfizer, New York, New York) and $10 \mathrm{mg} / \mathrm{kg}$ xylazine hydrochloride (Rompun, $50 \mathrm{~mL}$, 2\% flacon, Bayer, Pittsburgh, Pennsylvania). Rats were left naturally breathing during the operation. An $\sim 3-\mathrm{cm}$ vertical skin incision extending from the upper border of the thyroid cartilage under the maxilla at midline to the incisura jugularis was made. The skin and subcutaneous tissue were incised, and muscles were separated and retracted laterally at the laryngotracheal groove (Fig. 1). A vertical incision of $\sim 0.5 \mathrm{~cm}$ was made at the front of the second and fifth tracheal rings of all the rats and included 3 cartilages (Fig. 1). In each rat, the membranous part of the trachea was preserved. The tracheal incision was sutured with 4/0 Polyglactin 910 (Vicryl, Ethicon, St-Stevens-Woluwe, Belgium).

In Group A (control group), the tracheal incision area was only sutured. In Group B, a chitosan-based film layer was placed on the area of the tracheal incision. In Group C, a slow-release TGF- $\beta 3 /$ chitosan-based film layer $(5 \times 5 \mathrm{~mm})$ was placed on the sutured region (see Fig. 1).

On day 30, all rats in all 3 groups were killed by a high dose of isoflurane (İsofludem, Dem, Istanbul, Turkey) via an inhalation anesthesia apparatus. The trachea (with the esophagus) of each rat was removed by cutting the upper edge of the thyroid cartilage and the lower part of the sixth tracheal ring. During the study, all surgical operations were performed with the same surgical instruments by the same person to maintain standardization.

The tracheas were separately numbered in each group for microscopic examination and then subjected to blind examination by a pathologist with experience regarding

\section{QUICK LOOK}

\section{Current knowledge}

Tracheal stenosis is a common and serious complication of thoracic surgery. Bronchoscopic dilatation, stent placement, laser treatment, and surgical resection and reconstruction are common treatments. Nonsurgical treatments are not routinely performed.

\section{What this paper contributes to our knowledge}

In a small animal model of tracheal repair, the addition of transforming growth factor beta 3 in a chitosan base did not alter healing or reduce scar formation. The lack of effect might be explained by the inability to deliver transforming growth factor beta 3 in sufficient amounts.

the pulmonary system and with this kind of study in our hospital. For microscopic examination, incisions were fixed with $10 \%$ neutral formalin.

Epithelialization, inflammation, angiogenesis, fibroblast proliferation, and collagen levels were reviewed by histopathologic examination. All parameters were qualified as none $(-)$, mild $(+)$, moderate $(++)$, high $(+++)$, and excessive $(++++)$. In the course of the microscopic evaluation, the parameters were converted into numerical values of $0-4$ for statistical evaluation (Table 1).

For statistical analysis, SPSS 13.0 (SPSS, Chicago, Illinois) was used. The Pearson chi-square test and chisquare test for trend were used for statistical evaluation of the epithelialization, inflammation, angiogenesis, fibroblast, collagen, and complication results from the 3 groups. Results were evaluated at 95\% CI $(P<.05)$ and at 99\% CI $(P<.01)$.

\section{Results}

The rats were monitored up to termination for respiratory distress, stridor, and nutritional disorders. In the first week of the study, 2 rats from group C (TGF- $\beta 3 /$ chitosan) and one rat from group B (chitosan) died of general malignancy related to a nutritional disorder. Although no other abnormal situation was encountered over the following 2 weeks, one rat from group C, one rat from group B, and one rat from group A (control) died. No new rats were added because the number of rats was sufficient statistically. After a 30-day surveillance, 7 rats in group C, 8 rats in group B, and 9 rats in group A were killed.

Massive lesions of different dimensions were palpated in the tracheal incision areas of 4 rats from group $C$ (the combination group of TGF- $\beta 3 /$ chitosan) and 5 rats from group B (the chitosan group) (Fig. 2). A complication of 

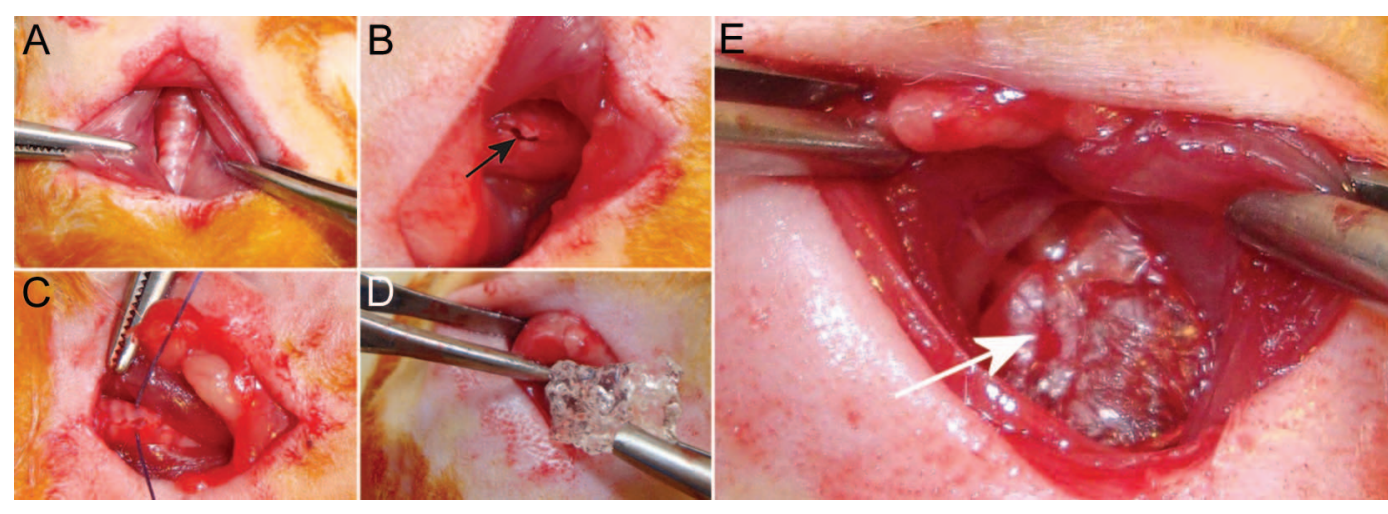

Fig. 1. A: Appearance of the trachea after dissecting strap muscles laterally. B: Tracheal incision. C: Suturing the incision of the trachea. D: Placement of the transforming growth factor beta3/chitosan preparation into the incision line. E: Surgical field after placing the preparation.

Table 1. Distribution of Inflammation in Groups and Among Groups

\begin{tabular}{|c|c|c|c|c|}
\hline Inflammation & $\begin{array}{c}\text { TGF- } \beta 3 \\
\text { (Group C) }\end{array}$ & $\begin{array}{l}\text { Chitosan } \\
\text { (Group B) }\end{array}$ & $\begin{array}{c}\text { Control } \\
\text { (Group A) }\end{array}$ & Total \\
\hline \multicolumn{5}{|l|}{ Mild (+) } \\
\hline Subjects, $n$ & 3 & 4 & 4 & 11 \\
\hline Inflammation, $\%$ & 27.3 & 36.4 & 36.4 & 100.0 \\
\hline Group, \% & 42.9 & 50.0 & 44.4 & 45.8 \\
\hline \multicolumn{5}{|l|}{ Moderate $(++)$} \\
\hline Subjects, $n$ & 2 & 1 & 2 & 5 \\
\hline Inflammation, $\%$ & 40.0 & 20.0 & 40.0 & 100.0 \\
\hline Group, \% & 28.6 & 12.5 & 22.2 & 20.8 \\
\hline \multicolumn{5}{|l|}{$\operatorname{High}(+++)$} \\
\hline Subjects, $n$ & 1 & 3 & 2 & 6 \\
\hline Inflammation, $\%$ & 16.7 & 50.0 & 33.3 & 100.0 \\
\hline Group, \% & 14.3 & 37.5 & 22.2 & 25.0 \\
\hline \multicolumn{5}{|l|}{ Excessive $(++++)$} \\
\hline Subjects, $n$ & 1 & 0 & 1 & 2 \\
\hline Inflammation, $\%$ & 50.0 & 0.0 & 50.0 & 100.0 \\
\hline Group, \% & 14.3 & 0.0 & 11.1 & 8.3 \\
\hline \multicolumn{5}{|l|}{ Total } \\
\hline Subjects, $n$ & 7 & 8 & 9 & 24 \\
\hline
\end{tabular}

the massive lesions was that they were paratracheal lesions. There were no complications encountered in the control group. Histopathologic examination demonstrated that the lesions in groups $\mathrm{B}$ and $\mathrm{C}$ were similar and identified the lesions as cold abscesses (Fig. 2).

Our aim was to provide a preparation that could release TGF- $\beta 3$ slowly and affect all levels of wound healing. Before this study, we used chitosan in rats. We did not observe any cold abscess formation. However, in this study, cold abscess formation was observed in both the chitosan and TGF- $\beta 3 /$ chitosan groups. As far as we know, there are no other slow-release preparations. In future studies, we will attempt to make a better slow-release TGF- $\beta 3$ preparation.

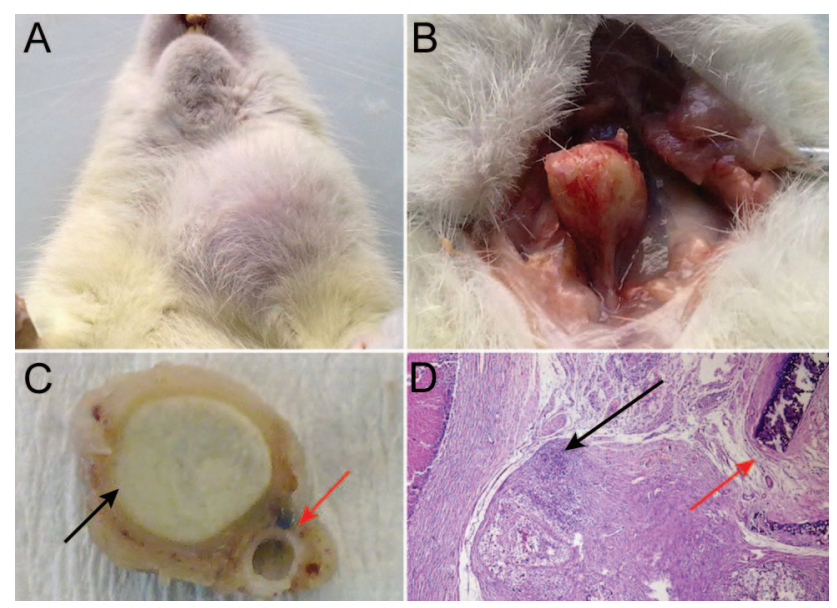

Fig. 2. A: Appearance of the mass palpated in the suture line in the surgical field. B: Abscess formation over the trachea. C: Crosssection view of the trachea and abscess. The black arrow indicates the abscess, and the red arrow indicates the tracheal incision line. D: Microscopic appearance of the abscess and trachea (hematoxylin and eosin stain, magnification $\times 40$ ). The black arrow indicates the abscess, and the red arrow indicates the tracheal incision line.

We also used this tracheal surgery model before and did not observe any abscess formation, and we did not use any antibiotics. In this study, we did not observe any symptoms of infection in the rats. There was no local erythema or heat in the surgical area. There was also no sign of infection as determined by pathological studies, so we did not take specimens for culture. The skin wounds healed without any complications, so we thought they were cold abscess due to foreign-body reactions.

The chi-square test was used to determine whether there was a statistically significant difference among the TGF- $\beta 3 /$ chitosan group (group C), the chitosan group (group B), and the control group (group A). From the point of complications, the difference between the groups was statistically significant. 
TGF- $\beta 3$, Wound Healing, And Stenosis Development

Table 2. Distribution of Collagen in Groups and Among Groups

\begin{tabular}{ccccc}
\hline \hline Collagen & $\begin{array}{c}\text { TGF- } \beta 3 \\
\text { (Group C) }\end{array}$ & $\begin{array}{c}\text { Chitosan } \\
\text { (Group B) }\end{array}$ & $\begin{array}{c}\text { Control } \\
\text { (Group A) }\end{array}$ & Total \\
\hline None $(-)$ & & & & \\
$\quad$ Subjects, $n$ & 1 & 1 & 7 & 9 \\
Collagen, $\%$ & 11.1 & 11.1 & 77.8 & 100.0 \\
Group, $\%$ & 14.3 & 12.5 & 77.8 & 37.5 \\
Mild $(+)$ & & & & \\
Subjects, $n$ & 2 & 4 & 0 & 6 \\
Collagen, $\%$ & 33.3 & 66.7 & 0.0 & 100.0 \\
Group, $\%$ & 28.6 & 50.0 & 0.0 & 25.0 \\
Moderate $(++)$ & & & & \\
Subjects, $n$ & 4 & 2 & 0 & 6 \\
Collagen, $\%$ & 66.7 & 33.3 & 0.0 & 100.0 \\
Group, $\%$ & 57.1 & 25.0 & 0.0 & 25.0 \\
High (+++) & & & & \\
Subjects, $n$ & 0 & 1 & 2 & 3 \\
Collagen, $\%$ & 0.0 & 33.3 & 66.7 & 100.0 \\
Group, $\%$ & 0.0 & 12.5 & 22.2 & 12.5 \\
Total & & & & \\
Subjects, $n$ & 7 & 8 & & \\
\hline TGF- $\beta 3=$ transforming growth factor beta3 & & & \\
\hline
\end{tabular}

Lumen narrowing was seen in all groups. We preferred to compare microscopic findings between the groups. We did not calculate the tracheal lumina, but all tracheal sections were prepared from the narrowest part of the tracheas.

Moreover, we did not examine tracheal stenosis directly because of the short study time. We aimed to evaluate wound healing and to measure epithelialization, fibroblast proliferation, angiogenesis, inflammation, and collagen levels, as these are thought to lead to tracheal stenosis.

The chi-square test was used to evaluate whether there was a statistically significant difference between the TGF- $\beta 3$ /chitosan group (group C), the chitosan group (group B), and the control group (group A) with regard to epithelialization, inflammation, angiogenesis, fibroblast proliferation, and collagen levels. For all parameters, statistically significant differences were not found among the groups $(P>.05)$. The results of the histopathologic examinations are shown in Tables 1-4.

\section{Discussion}

Tracheal surgery is performed as a curative method in most cases, although it is sometimes difficult in terms of anatomic and technical aspects. Tracheal resection is frequently used for tracheal tumors, stenosis, trauma, congenital anomalies, and vascular lesions. The primary and most important complication of surgical treatments is recurrent stenosis related to formation of granulation tissue. ${ }^{3}$
Table 3. Distribution of Epithelium Regeneration in Groups and Among Groups

\begin{tabular}{|c|c|c|c|c|}
\hline Epithelium & $\begin{array}{c}\text { TGF- } \beta 3 \\
\text { (Group C) }\end{array}$ & $\begin{array}{l}\text { Chitosan } \\
\text { (Group B) }\end{array}$ & $\begin{array}{c}\text { Control } \\
\text { (Group A) }\end{array}$ & Total \\
\hline \multicolumn{5}{|l|}{ None $(-)$} \\
\hline Subjects, $n$ & 0 & 1 & 0 & 1 \\
\hline Epithelium, \% & 0.0 & 100.0 & 0.0 & 100.0 \\
\hline Group, \% & 0.0 & 12.5 & 0.0 & 4.2 \\
\hline \multicolumn{5}{|l|}{ Mild (+) } \\
\hline Subjects, $n$ & 4 & 1 & 2 & 7 \\
\hline Epithelium, \% & 57.1 & 14.3 & 28.6 & 100.0 \\
\hline Group, \% & 57.1 & 12.5 & 22.2 & 29.2 \\
\hline \multicolumn{5}{|l|}{ Moderate $(++)$} \\
\hline Subjects, $n$ & 2 & 3 & 4 & 9 \\
\hline Epithelium, \% & 22.2 & 33.3 & 44.4 & 100.0 \\
\hline Group, \% & 28.6 & 37.5 & 44.4 & 37.5 \\
\hline \multicolumn{5}{|l|}{$\operatorname{High}(+++)$} \\
\hline Subjects, $n$ & 1 & 3 & 3 & 7 \\
\hline Epithelium, \% & 14.3 & 42.9 & 42.9 & 100.0 \\
\hline Group, \% & 14.3 & 37.5 & 33.3 & 29.2 \\
\hline
\end{tabular}

Table 4. Distribution of Angiogenesis in Groups and Among Groups

\begin{tabular}{lcccc}
\hline \hline Angiogenesis & TGF- $\beta 3$ & Chitosan & Control & Total \\
\hline None (-) & 0 & 0 & 1 & 1 \\
$\quad$ Subjects, $n$ & & & & \\
$\quad$ Angiogenesis, $\%$ & 0.0 & 0.0 & 100.0 & 100.0 \\
$\quad$ Group, $\%$ & 0.0 & 0.0 & 11.1 & 4.2 \\
Mild (+) & & & & \\
$\quad$ Subjects, $n$ & 3 & 3 & 4 & 10 \\
$\quad$ Angiogenesis, $\%$ & 30.0 & 30.0 & 40.0 & 100.0 \\
$\quad$ Group, $\%$ & 42.9 & 37.5 & 44.4 & 41.7 \\
Moderate (++) & & & & \\
$\quad$ Subjects, $n$ & 2 & 2 & 3 & 7 \\
$\quad$ Angiogenesis, $\%$ & 28.6 & 28.6 & 42.9 & 100.0 \\
$\quad$ Group, $\%$ & 28.6 & 25.0 & 33.3 & 29.2 \\
High (+++) & & & & \\
$\quad$ Subjects, $n$ & 2 & 3 & 1 & 6 \\
$\quad$ Angiogenesis, $\%$ & 33.3 & 50.0 & 16.7 & 100.0 \\
$\quad$ Group, $\%$ & 28.6 & 37.5 & 11.1 & 25.0 \\
Total & & & & \\
$\quad$ Subjects, $n$ & 7 & 8 & 9 & 24 \\
& & & & \\
\hline TGF- $\beta 3=$ transforming growth factor beta3 & & & \\
\hline
\end{tabular}

Some treatments are used to avoid the formation of granulation tissue and any one of the 3 stages of wound healings: stage 1 (inflammation phase), antibiotics, corticosteroids, and hyperbaric oxygen therapy; stage 2 (proliferation phase), antibiotics, corticosteroids, mitomycin $\mathrm{C}$, combination of 5-fluorouracil and triamcinolone 
acetate, carnitine, and hyperbaric oxygen therapy; and stage 3 (maturation phase), halofuginone, $\beta$-aminopropionitrile, colchicine, penicillamine, and $N$-acetyl-L-cysteine.

Research was conducted for new treatment methods to prevent granulation formation in patients with tracheal stenosis. In a study conducted using estrogen and progesterone, Liman et $\mathrm{al}^{6}$ showed that sex hormones prevent massive collagen and fibroblast proliferation in wound healing after tracheal surgery.

Mitomycin C was used for treatment of tracheal stenosis for the first time in 1998 and is the most researched drug for this purpose. ${ }^{5}$ Although it is not clear some results show that mitomycin $\mathrm{C}$ decreases fibroblast proliferation. Also, it is has been shown that mitomycin $\mathrm{C}$ slows wound healing during the inflammation and proliferation stages by decreasing basic fibroblast growth factor and TGF- $\beta 1$ levels. ${ }^{7}$

Studies show that TGF- $\beta 3$, which was used in this study, is successfully used in topical form for treatment of hypertrophic scar tissues. Hirshberg et $\mathrm{al}^{8}$ reported that the gel form of TGF- $\beta 3$ has been used topically for bedsores and was very effective. Squier et $\mathrm{al}^{9}$ researched the permeability and stability of TGF- $\beta 3$ used topically on oral mucosa. They found that the tissue permeability of topical TGF- $\beta$ on oral mucosa was adequate, and a sufficient concentration was obtained for target tissue.

As understood from the mechanism of the effect of mitomycin C, TGF- $\beta 3$ is an anabolic cytokine that has an important role in wound healing and shaping scars. TGF- $\beta 1$ and TGF- $\beta 2$ cause fibrosis by inhibiting collagen production of fibroblasts and extracellular matrix destruction of metalloproteases. Although TGF- $\beta 1$ is profibrotic, TGF- $\beta 3$ has an antifibrotic effect. In their studies of an experimental model of rat wounds, Shah et $\mathrm{al}^{10}$ identified a decline in their control group's collagen deposits in the wound area as a result of TGF- $\beta 1$, TGF- $\beta 2$-neutralizing antibody, and exogen TGF- $\beta 3$ usage. TGF- $\beta 3$ was used in this study mainly because it affects all stages of wound healing, especially the proliferative phase.

Loewen et al ${ }^{11}$ conducted research by traumatizing cricoid cartilage in rats and applied $1 \mu \mathrm{g}$ of TGF- $\beta 3$ to one group and $0.18 \mu \mathrm{g}$ of TGF- $\beta 3$ to another group. They compared the control group with both groups. The results indicated that the group given $1 \mu \mathrm{g}$ of TGF- $\beta 3$ showed the best epithelialization and that the other groups did not show a significant change. No significant difference in inflammation levels was found among the 3 groups.

We preferred an anterior incision over a full tracheal resection because we wanted to damage the trachea but did not want to intubate the animals. Full tracheal resection would require intubation. We chose the easier way to damage the trachea. Anterior incision (extending from the second to fifth tracheal rings) provided more damaged tissue area for us to work with. We also made a preparation of
TGF- $\beta 3$ and used it to cover the injury site completely. We tried to avoid esophageal injury and complications from esophageal trauma.

In this study, the dosage of TGF- $\beta 3$ was determined in accordance with the literature, and slow-release preparations containing TGF- $\beta 3$ at a dose of $1 \mu \mathrm{g}$ combined with chitosan were prepared. Chitosan was chosen because it is widely used in pharmaceutical preparations of various dosage forms such as microspheres, nanoparticles, microcapsules, and film and tablet formations.

Also, chitosan was preferred as a base because of its use in the biomedical area and its degradability, toxicity, and hemostatic functions. In addition, it accelerates wound healing, has antimicrobial, antiviral, and hypocholesterolemic activities, and is compatible with the body. That the complication of abscess development was observed in the TGF- $\beta /$ chitosan and chitosan groups but not in the control group indicates that the cause could be the chitosan. However, this issue should be examined through further research, as there have been no reported complications regarding chitosan.

In our study, we also aimed to make a slow-release preparation with a chitosan base that would affect all levels of wound healing. We considered that foreign-body reactions cause inflammation and prevent release of TGF$\beta 3$. TGF- $\beta 3$ is in powder form. Preparing a solution is possible, but it would not provide coverage of the entire injured area. It would disperse into the neck tissue, which is why we preferred to make a film preparation with chitosan. In addition, there is no other preparation of TGF- $\beta 3$ that is suitable. Therefore, we are planning to carry out a new experimental study using a different slow-release form.

The results of this study are not in accordance with the literature. TGF- $\beta 3$ was not found to be effective in wound healing. Contrary to the hypothesis, the reduction in collagen levels and fibrosis could not be observed in airway wound healing. An abscess that had been caused by chitosan could prevent TGF- $\beta 3$ from penetrating target tissue. There was excessive collagen formation and tracheal lumen narrowing. We cannot say that TGF- $\beta 3$ was ineffective, but we can say that we could not show the effect of TGF- $\beta 3$ because of the abscesses, which might affect the wound-healing process. However, this complication of chitosan should be known.

There are 2 stages in the tissue reaction against slowrelease film-layer preparations. In the first stage, a fibrous capsule encircles the preparation. In the second stage, a foreign-body reaction occurs in the surroundings of the microcapsules. These events occur faster than degradation of the material. Spaces between microcapsules in slowrelease film material are filled with macrophages and fibroblasts, which are the basic elements of granulation formation. Fibroblasts produce collagen, and fibrous tissue is formed. In these circumstances, a very small number of 
effective microcapsules are left. In the last stage, vascular capillaries disappear, and the fibrous capsule is constricted. Collagen fibers become compact, and the remaining effective microcapsules are trapped. Because of these histopathologic changes, we believe that TGF- $\beta 3$ did not reach the injured tissue effectively in our study.

This was the first documented use of a slow-release preparation of TGF- $\beta 3$ in tracheal surgery in the literature. We believe that a sufficient tissue concentration could not be achieved because of the abscesses caused by the chitosan base. However, this study suggests the need for further research on the use of TGF- $\beta 3$ to prevent granulation tissue formation after tracheal surgery.

\section{REFERENCES}

1. Correa AJ, Reinisch L, Sanders DL, Haung S, Deriso W, Duncavage JA, Garrett CG. Inhibition of subglottic stenosis with mitomycin-C in the canine model. Ann Otol Rhinol Laryngol 1999;108(11 Pt 1):1053-1060.

2. Ertuğrul EE, Cincik H, Dogru S, Cekin E, Berber U, Gungor A, Poyrazoğlu IE. Effects of halofuginone on fibrosis formation secondary to experimentally induced subglottic trauma. Laryngoscope 2007;117(2):299-302.
3. Eliashar R, Eliachar I, Esclamado R, Gramlich T, Strome M. Can topical mitomycin prevent laryngotracheal stenosis? Laryngoscope 1999;109(10):1594-1600.

4. Bennett NT, Schultz GS. Growth factors and wound healing: biochemical properties of growth factors and theirs receptors. Am J Surg 1993;165(6):728-737.

5. Hirshoren N, Eliashar R. Wound-healing modulation in upper airway stenosis-myths and facts. Head Neck 2009;31(1):111-126.

6. Liman ST, Kara CO, Bir F, Yildirim B, Topcu S, Sahin B. The effects of estradiol and progesterone on the synthesis of collagen in tracheal surgery. Int J Pediatr Otorhinolaryngol 2005;69(10): 1327-1331.

7. Chen T, Kunnavatana SS, Koch RJ. Effects of mitomycin-C on normal dermal fibroblasts. Laryngoscope 2006;116(4):514-517.

8. Hirshberg J, Coleman J, Marchant B, Rees RS. TGF-beta3 in the treatment of pressure ulcers: a preliminary report. Adv Skin Wound Care 2001;14(2):91-95.

9. Squier CA, Kremer MJ, Bruskin A, Rose A, Haley JD. Oral mucosal permeability and stability of transforming growth factor beta- 3 in vitro. Pharm Res 1999;16(10):1557-1563.

10. Shah M, Foreman DM, Ferguson MW. Neutralization of TGF- $\beta 1$ and TGF- $\beta 2$ or exogenous addition of TGF- $\beta 3$ to cutaneous rat tissue wound reduces scarring. J Cell Sci 1995;108(Pt 3):985-1002.

11. Loewen MS, Walner DL, Caldarelli DD. Improved airway healing using transforming growth factor beta-3 in a rabbit model. Wound Repair Regen 2001;9(1):44-49. 